\title{
Efficient partnership dissolution under buy-sell clauses
}

\author{
María-Angeles de Frutos* \\ and \\ Thomas Kittsteiner**
}

Buy-sell clauses are commonly used contractual provisions to determine the terms of dissolution of partnerships. Under them, one party offers a price for the partnership and the other party chooses whether to sell her share or buy her partner's share at this price. We point out that the selection of the proposing partner is essential for the performance of the clause. Moreover, if partners negotiate for the advantage of being the chooser, then buy-sell clauses result in an ex post efficient outcome. Such endogenous selection is consistent with how buy-sell clauses are drafted in practice.

\section{Introduction}

Partners in commercial relationships have to think about the possibility that the partnership might end. A management deadlock such as a fundamental disagreement about the future strategy of the commonly owned firm might lead to the inevitability of splitting up. Due to market inefficiencies and frictions, it is sometimes more sensible for one partner to buy out the other and realize the profits than to liquidate and sell the company to a third party. ${ }^{1}$ Being aware of this, business attorneys recommend including a buy-sell clause (commonly referred to as shotgun clause) in the initial partnership agreement to govern the dissolution process. In brief, a buy-sell clause is a deadlock resolution mechanism that works as follows: one party proposes a price, and the other decides whether to buy or sell at that price. Actually, the buy-sell clause is considered to be such an essential part of partnership agreements, that a lawyer who fails to recommend to his

\footnotetext{
*Universidad Carlos III de Madrid; frutos@eco.uc3m.es.

** London School of Economics and Political Science; T.M.Kittsteiner@1se.ac.uk.

We have benefited from comments by Richard Brooks, Erik Eyster, Paul Klemperer, Wolfgang Köhler, Meg Meyer, Benny Moldovanu, Nicola Persico, Georges Siotis, Kathy Spier, anonymous referees, the editor, as well as participants at the Second Game Theory World Congress in Marseille (July 2004) and at the Economic Design Conference in Mallorca (June 2004). The authors would like to thank Nuffield College, Oxford, for its hospitality and support during the preparation of this article. The first author's research was supported by the Spanish Ministerio de Educación (grant SEJ 2007-67436).

${ }^{1}$ Studying a sample of 297 two-parent U.S. joint ventures, Hauswald and Hege (2003) report that in $34 \%$ of them there was a buyout and in $20 \%$ there was either a liquidation or sale to a third party.
} 
clients adopting one could be accused of malpractice. ${ }^{2}$ Thus, not surprisingly, real-life examples of partnerships that include buy-sell clauses in their partnership agreements abound. ${ }^{3}$

Buy-sell clauses have also caught the attention of economic theorists. In the case where partners' valuations are private information, reflecting what they know about their ability to run the business, economists do not recommend buy-sell clauses for solving a deadlock (see McAfee, 1992). Contrary to legal advice, they have stressed that buy-sell clauses could result in inefficient dissolutions, that is, the business may not end up in the hands of the partner who values it most. When partners only know their own valuation, the proposer has to set a price based on her estimate of her partner's valuation. She offers a price above (below) her valuation if she believes that she is likely to sell (buy), that is, her partner's valuation is likely to be higher (lower) than her own. Consequently, whenever her partner's valuation lies between her own and the price, she becomes a buyer, whereas efficiency requires her to sell. Similarly, when the other party's valuation lies between the price and hers, she inefficiently becomes the seller. Given this negative result, auctions have been suggested as an efficient solution to the dissolution problem (see Cramton, Gibbons, and Klemperer, 1987; McAfee, 1992). ${ }^{4}$

Nevertheless, the inefficiency argument against the buy-sell clause does not have bite if the right party is called to name the price. When both partners have low valuations (and would hence propose a price above their valuation), an efficient dissolution is guaranteed if the partner with the higher valuation proposes the price. Also, if both partners have high valuations, efficiency is guaranteed if the partner with the lower valuation proposes. If one partner's valuation is below the median and the other's is above, then either party proposing the price ensures efficiency. The determination of the proposer is then crucial for efficiency.

From a legal point of view, a buy-sell clause consists of two parts: a specification of the circumstances under which it applies and a description of what the partners are obliged to do in case it applies. The first part defines when a management deadlock (MD) is deemed to occur. The second part prescribes a set of actions in chronological order. It states that (possibly after a cooling-off period), either party can serve a so-called deadlock option notice, which is irrevocable, and specifies a single price at which the party giving notice (the proposer) offers to either sell all her shares at the specified price or purchase all shares held by the other party at this specified price. After receiving the deadlock option notice the other party shall, at its sole option, elect either (i) to purchase all of the shares at the price stated in the deadlock option notice, or (ii) to require the proposer to purchase all of the shares held by that other party at the price stated in the deadlock option notice. ${ }^{5}$ The formulation of the buy-sell clause reveals that it only applies to two-parent partnerships. Furthermore, most corporate lawyers recommend its use only if both partners own (roughly) the same share in the firm (see, e.g., Hewitt, 2005). It is worth noting that the buy-sell clause covers neither the contingency where no party proposes a price nor the contingency where both propose a price. Moreover, it does not resolve the question of who has to propose. Parties who disagree on this issue might ask a court to dissolve the partnership, as the legal case Hotoyan v. Jansezian illustrates. Two partners who had signed an agreement that included a buy-sell clause went to the Ontario Court as they disputed the matter of who had to go first (see O.J. no. 4486, Court File no. 99-CL-3263, 1999).

${ }^{2}$ For example, the Guide to U.S. Real Estate Investing issued by the Association of Foreign Investors in Real Estate states that "such a [buy-sell] clause is usually thought of as the ultimate mechanism for resolving disputes." See also Brooks and Spier (2004).

${ }^{3}$ The following partnerships all included buy-sell clauses: the German TV channel VOX (between CLT-UFA and News Corporation); the New York-New York Hotel (between Primadonna Resorts Inc. and MGM Grand Inc.); and the "Original Levi’s Stores" (between Levi Strauss \& Co. and Designs Inc.).

${ }^{4}$ Surprisingly, auctions are rarely considered as an alternative to buy-sell clauses in the literature on corporate law. Hoberman (2001), when discussing alternatives to the buy-sell clause, does not even mention auctions. The same is true for books devoted to the drafting of shareholders' agreements (see, e.g., Cadman, 2004; Stedman and Jones, 1990).

${ }^{5} \mathrm{~A}$ blueprint of a buy-sell clause can be found in Precedent 10, in Hewitt (2005). The descriptions of the clause in Cadman (2004) or Stedman and Jones (1990) are also consistent with the one reported here. 
An alternative way of settling the issue as to who has to propose was taken by Comcast UK and Telewest, each a 50\% owner of the Cable London franchise. After 16 years of partnership, in February 1998, Comcast announced its intention to sell its cable interest to the NTL group. This announcement resulted in negotiations between Comcast UK and Telewest for the dissolution of their partnership. In August 1998, the Telewest spokesman announced that they had "solved an ambiguity in the original ownership agreement." They agreed that by no later than 30 September 1999, Comcast (or NTL after the amalgamation with Comcast) would notify Telewest of a price at which Telewest would be required either to purchase or sell. The buyout was completed in August 1999 with Comcast/NTL proposing a price of approximately $£ 428$ million to Telewest, who decided to buy. The agreement between Telewest and Comcast suggests that a buy-sell clause may be used after a negotiation stage to identify the proposer. ${ }^{6}$

Because the buy-sell clause (as formulated in partnership agreements) does not prespecify a certain partner as proposer but rather allows for the proposer to be selected endogenously by the partners if a deadlock arises, we model here the dissolution game induced by a buy-sell clause. In accordance with contractual formulations in partnership agreements, we study the performance of buy-sell clauses taking into account that parties may negotiate over the identity of the proposer, simply wait for the other party to propose, or end up in court. Our main analysis covers the classical private values environment as introduced by Cramton, Gibbons, and Klemperer (1987) and McAfee (1992). We show that if partners negotiate the role of proposer (and these negotiations start without delay after the deadlock occurs), then the partnership is dissolved efficiently, that is, the partner with the higher valuation buys all shares.

We model the negotiations as an ascending auction with parties bidding for the right to choose. It can be thought of as a simplified model of a negotiation procedure in which parties make alternating offers for the right to choose. We show that when partners take into account the information that will be revealed through their negotiations, the party with the valuation closer to the median valuation will propose and, hence, an efficient dissolution will take place. If partners engage in costly waiting for the other to propose the price (which we model as a war of attrition), the partner with the higher valuation will finally buy. As in this environment there are inefficiencies due to costly waiting, partners would agree to engage in negotiations rather than to wait. We also analyze a framework where partners are free to negotiate, delay, or name a price at any time. We show that in an equilibrium they will negotiate immediately and dissolve the partnership efficiently.

To investigate the robustness of the efficiency results, we also consider the buy-sell clause in an interdependent values model with one-sided private information, which is based on Jehiel and Pauzner (2006). We find that the buy-sell clause, though it does not achieve full efficiency, outperforms other possible dissolution mechanisms; in particular, it is better than an auction.

Our results may concern academics as well as practitioners. From a normative point of view, our analysis gives a justification as to why buy-sell clauses cannot be ruled out on the grounds of efficiency alone. In a private values model, we show that they cannot be dismissed on efficiency issues; furthermore, with interdependent valuations, they could even be advisable on the grounds of efficiency. From a positive point of view, we argue that practitioners need to make partners aware of the option to negotiate the right to choose, as this might not be explicitly stated in the partnership agreement and may avoid a costly war of attrition and/or costly and inefficient court rulings. In sum, the buy-sell clause is capable of rendering efficient dissolutions, so if efficiency is the only goal, there is no reason for not using it.

This article is organized as follows. In Section 2, we introduce the private values model and briefly discuss the buy-sell clause with a predefined proposer (as analyzed in McAfee, 1992). In Section 3, we first analyze the performance of buy-sell clauses if partners negotiate who proposes.

${ }^{6}$ Details about this case can be found in press releases of Telewest; see particularly those dated 8-17-1998 and 7-25-1999. These press releases also state how Telewest agreed to acquire Birmingham Cable for £125 million. We perceive that these transfers incorporate the payment Telewest had to make to be the chooser. 
We then compare this to the situation where partners wait for the other to propose and, finally, we present a unified framework that incorporates negotiations and delay. In Section 4, we discuss the performance of the clause for an interdependent values model. Section 5 contains our conclusions. Finally, proofs are relegated to the Appendix.

\section{The model}

We study partnership dissolution in a symmetric independent private values framework. Two risk-neutral partners, 1 and 2, have valuations $v_{1}$ and $v_{2}$, respectively, for the sole ownership of the business. ${ }^{7}$ Valuations are independently and identically distributed according to a cdf $F$ with continuous density $f>0$ and support $[0,1]$. Even though the valuation $v_{i}$ is private to partner $i$, reflecting what she knows about her ability to run the business, the model does not preclude partners from sharing information on a common value component of the business (such as employee structure, assets, financial situation, etc.). Each partner owns an equal share of the partnership. ${ }^{8}$ An agent's utility is linear in money and share, that is, the utility of partner $i$ who holds a share of $\alpha$ in the partnership and receives a payment $m$ is given by $U_{i}=\alpha v_{i}+m$.

A desirable property for a dissolution mechanism (such as the buy-sell clause) to have is that it allocates the (shares of the) partnership efficiently. An allocation is said to be efficient if the partner with the highest valuation receives the entire partnership. A dissolution mechanism is (ex post) efficient if there exists an equilibrium in which the partner with the higher valuation gets the entire partnership and no money is wasted.

In the buy-sell clause one party specifies a price (the proposer), and the other party decides whether to buy or sell at that price (the chooser). If $p$ is the price specified by the proposer, the chooser selects either $p / 2$ or the business, in which case she pays the proposer $p / 2$. It can easily be verified that the chooser decides to take the money as long as the price $p$ is larger than her valuation; otherwise, she decides to buy her partner's share.

If one of the partners proposes a price $p$ (immediately after the deadlock occurs), this proposer's expected utility (or expected payoff) is

$$
\begin{aligned}
U^{P}\left(v_{P}, p\right) & =\left(v_{P}-p / 2\right) \operatorname{Pr}\left(v_{C} \leq p\right)+(p / 2) \operatorname{Pr}\left(v_{C}>p\right) \\
& =\left(v_{P}-p\right) F(p)+p / 2,
\end{aligned}
$$

where subscripts $P$ and $C$ stand for proposer and chooser, respectively. In what follows, we assume that the standard hazard rate conditions are satisfied ${ }^{9}$ :

$$
\frac{d}{d x}\left(x+\frac{F(x)}{f(x)}\right) \geq 0 \text { and } \frac{d}{d x}\left(x-\frac{1-F(x)}{f(x)}\right) \geq 0 .
$$

Let us define the revenue-maximizing price for the proposer by $p^{*}\left(v_{P}\right)=\arg \max _{p} U^{P}\left(v_{P}, p\right)$, and the derivative of $U^{P}$ with respect to its second argument by $U_{2}^{P}$. It is important to note that the proposer's optimal strategy depends on the distribution of the chooser's valuation, whereas the chooser's optimal strategy depends only on the proposed price $p$ and her own valuation $v_{C}$. (It is therefore independent of any distributional assumptions.)

The next proposition characterizes the equilibrium price set by the proposer and some of its properties. Let $v^{\text {med }}$ be the median valuation.

\footnotetext{
${ }^{7}$ From a sample of 668 worldwide alliances, Veugelers and Kesteloot (1996) report that more than $90 \%$ of the alliances only involve two parties.

${ }^{8}$ In Veugelers and Kesteloot's (1996) sample, even though the data cover partnerships between unevenly sized firms, more than 50\% exhibit 50-50 ownership. Similarly, in Hauswald and Hege's (2003) sample of two-parent joint ventures, about two thirds have 50-50 equity allocations.

${ }^{9}$ Under these conditions, the virtual valuation for a type who is a net seller is increasing in her valuation, that is, $\left(x+\frac{F(x)}{f(x)}\right)$. Similarly for the virtual valuation of a type who is a net buyer, $\left(x-\frac{1-F(x)}{f(x)}\right)$. Increasing hazard rates ensure that expected payments are increasing in valuations.
} 
Proposition 1 (McAfee, 1992). The optimal price $p^{*}\left(v_{P}\right)$ is the unique solution for $p$ to $U_{2}^{P}\left(v_{P}\right.$, $p)=0$. It is nondecreasing and satisfies $p^{*}\left(v_{P}\right)=v_{P}$ if $v_{P}=v^{\text {med }}, p^{*}\left(v_{P}\right)<v_{P}$ if $v_{P}>v^{\text {med }}$, and $p^{*}\left(v_{P}\right)>v_{P}$ if $v_{P}<v^{\text {med }}$.

The rationale behind the properties of the equilibrium price is as follows. If a partner with a valuation above the median sets a price equal to her own valuation, she will more likely end up buying the business. She would hence improve her payoff by reducing the buying price. By lowering the price, she would also sell to partners with a valuation slightly below her own, therefore making a loss on these trades. This loss is of second order, whereas the gain because of buying at a lower price is of first order. Similarly, if her valuation is below the median, she is better off setting a price above her valuation, as she is more likely the selling partner.

McAfee (1992) shows that using a buy-sell clause to dissolve a partnership may lead to inefficient allocations. The inefficiency might arise when partners' valuations are either both below or both above the median valuation. However, inefficiencies only arise when the wrong partner is proposing. To make this point clear, consider first the case that partners' valuations are both below the median. As either partner will name a price higher than her valuation, efficiency requires that the partner with the highest valuation proposes. Similarly, if valuations are both above the median, then an efficient allocation emerges whenever the partner with the smallest valuation proposes. This suggests that the partner with the lowest valuation should choose if both valuations are below the median, and propose if they are above the median. A natural question to ask then is whether an endogenous determination of the proposer can render efficient allocations and, if the answer is affirmative, whether the framing of the clause as can be found in partnership agreements allows for this to happen.

\section{Endogenous proposer selection}

- When a management deadlock comes forth, parties must decide on who proposes. Legal cases, such as those referred to in the Introduction, show that parties stuck in a deadlock have followed different routes, from waiting for the other to come forward with a price (and finally going to court) to reaching agreement through negotiations over who will propose. We study here the performance of these exit strategies. Because the dissolution games we consider are sequential games with incomplete information, our equilibrium concept is perfect Bayesian equilibrium.

Negotiating the right to choose. We first examine the outcome of a dissolution when partners must abide by the buy-sell clause in their shareholder agreement and they negotiate to determine the party entitled to choose. We consider a dissolution procedure which consists of two stages. In the first stage, the negotiation stage, partners determine who becomes the chooser and proposer. In the second stage, the pricing stage, they dissolve the partnership according to the rules of the buy-sell clause. We will refer to this sequential game as the dissolution game. The negotiation stage is modelled as an ascending auction with a fast clock on bids. Both parties raise their bids continuously, and either party can drop out of the auction at any time. The party who drops out becomes the proposer and receives a payment equal to the bid at which the auction ends. The ascending auction can be seen as a continuous version of an alternating-offer negotiation game. ${ }^{10}$

We solve the game assuming that negotiation strategies are U-shaped. We then show that the purported negotiation strategies are consistent with equilibrium behavior. In what follows, we also provide a rough intuition as to why partners negotiate in accordance with a U-shaped function.

The pricing stage. An important aspect of the dissolution game is that information about partners' valuations is revealed by the strategies played in the negotiation stage. The proposing

${ }^{10}$ The assumption of a continuously increasing price is a simplification and describes the limiting case of an offer game where partners increase their offers on a discrete price grid in an alternating order, until one of them drops out. 
FIGURE 1

THE PROPOSER'S INFERENCE AFTER THE NEGOTIATION STAGE

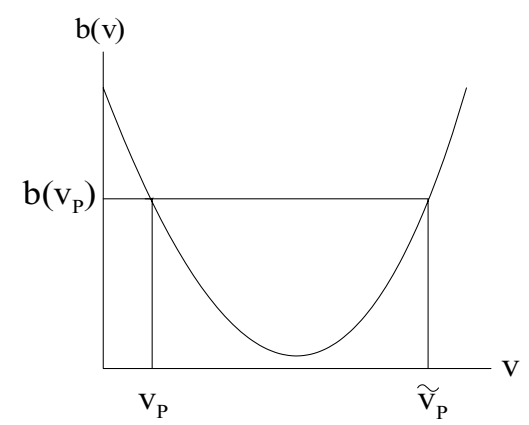

party hence updates her beliefs about the distribution of her partner's valuation. Information is only important for the proposer as the chooser's decision is belief independent. He only needs to compare his valuation with the proposed price.

As a starting point, we assume that there is an equilibrium in which bidding strategies are silent, such that no inference about valuations can be made. If this were the case, partners would always prefer to choose rather than propose and their willingness to pay for being entitled to choose would be U-shaped. ${ }^{11}$ Or more formally, if we denote the interim utility of the proposer and the chooser with valuation $v$ by $U^{P}(v)$ and $U^{C}(v)$, respectively, the difference $U^{C}(v)-$ $U^{P}(v)$ is strictly decreasing for $v<v^{\text {med }}$ and strictly increasing for $v>v^{\text {med }}$. The intuition for this result is that a chooser benefits from the fact that the proposer is uncertain about whether she will sell or buy. For example, consider the type $v^{\text {med }}$. If this type proposes, she optimally names her valuation as she is equally likely to be the buyer or seller. Her expected utility as proposer is hence half her valuation. As chooser, she faces prices close to her valuation. If they are higher, she sells and gets an expected utility slightly larger than half her valuation. If they are below, she buys, which also gives her an expected utility slightly above half her valuation. The difference in expected payoffs is hence strictly positive. ${ }^{12}$ This difference is even larger for "more extreme" valuations: as prices are set around $v^{\text {med }}$ (recall that prices are set between $v^{\text {med }}$ and the proposer's valuation), the difference between valuation and price is larger for a chooser with an "extreme" valuation. In addition, when these "extreme" types propose, they cannot set a price too close to $v^{\text {med }}$, as it would result in unprofitable trade with high probability. Consequently, they cannot take much advantage of their "extreme" valuations as proposer. This is why these extreme types have an even higher willingness to pay than types close to $v^{\text {med }}$.

To solve the pricing stage, we assume that bidding strategies are indeed U-shaped. As such strategies reveal information, the behavior of the losing party at the pricing stage takes into account what she learns from the negotiation stage. In particular, a losing party who bid $b(v)$ knows that the other party was willing to bid higher. Because of the U-shaped form of the bidding function, she further knows that there may exist another valuation $\widetilde{v}_{P}$ that would have dropped out at the same bid, that is, $b(v)=b\left(\widetilde{v}_{P}\right)$. Assuming that $\widetilde{v}_{P}>v_{P}$, the losing party concludes that her partner's valuation must be either above $\widetilde{v}_{P}$ or below $v_{P}$. Figure 1 illustrates this argument. The precise updating is the content of the next lemma.

\footnotetext{
See the proof of Theorem 9 in McAfee (1992).

${ }^{12}$ The preference to be the chooser also holds in a common values environment with incomplete information (see Morgan, 2004; Brooks and Spier, 2004).
} 
Lemma 1. If the bidding strategies at the negotiation stage are U-shaped, a proposer who bids $\widehat{b}$ has updated beliefs given by

$$
\begin{aligned}
F^{C}(x) & =\operatorname{Pr}\left(v_{C} \leq x \mid v_{C} \in\left[0, v^{*}\right) \cup\left(v^{* *}, 1\right]\right) \\
& = \begin{cases}\frac{F(x)}{F\left(v^{*}\right)+1-F\left(v^{* *}\right)} & \text { if } x \in\left[0, v^{*}\right) \\
\frac{F\left(v^{*}\right)}{F\left(v^{*}\right)+1-F\left(v^{* *}\right)} & \text { if } x \in\left[v^{*}, v^{* *}\right] \\
\frac{F(x)-F\left(v^{* *}\right)+F\left(v^{*}\right)}{F\left(v^{*}\right)+1-F\left(v^{* *}\right)} & \text { if } x \in\left(v^{* *}, 1\right],\end{cases}
\end{aligned}
$$

where $b\left(v^{*}\right)=b\left(v^{* *}\right)=\widehat{b}$ and $v^{*}<v^{* *}$. If $b\left(v^{*}\right)=b\left(v^{* *}\right)$ does not hold for two different types, then the updated distribution is given by the formula above with $b\left(v^{*}\right)=\widehat{b}$.

Furthermore, because $v^{\text {med }}$ is a natural candidate type for having the minimal willingness to pay, we assume (and confirm later) that the equilibrium bids are symmetric around this type. In particular, we assume that types $v$ and $s(v), v<v^{\text {med }}<s(v)$, bid the same amount $b(v)$, where $s(v):=F^{-1}(1-F(v))$ is the complementary quantile of $v$. An immediate consequence of this symmetry property is that in the pricing stage it is optimal for the proposer to set a price equal to her valuation.

Lemma 2. Assume partners bid according to a bidding function $b(v)$ in the negotiation stage that is strictly decreasing for $v<v^{\text {med }}$ and has the symmetry property $b(v)=b(s(v))$. Then a proposer with valuation $v_{P}$ optimally sets a price $p=v_{P}$ in the pricing stage and a chooser with valuation $v_{C} \neq v_{P}$ optimally buys if and only if $v_{C}>v_{P}$.

Note that what is needed for efficiency is the symmetry of the U-shaped bidding functions. This guarantees that the losing party assigns the same probability to the partner having a valuation larger than hers as she does to the partner having a valuation smaller than hers.

The negotiation stage. We now focus on the bidding functions that will be optimal for the partners. We first note that the overall utility of a partner in the dissolution game can be decomposed into her expected payoff in the pricing stage, plus the payments she expects to receive/pay from the negotiations. Equilibrium bidding strategies must reflect parties' willingness to pay to become chooser, which in our two-stage game is given by the expected payoff from the pricing stage and the expected transfers from the negotiation stage. As argued in the last subsection, a plausible conjecture is that bidding functions are $\mathrm{U}$-shaped and symmetric.

To investigate whether symmetry is consistent with equilibrium behavior, consider the effects of a small (marginal) change in the bids of types $v$ and $s(v)$. If this deviation had the same (marginal) effect on their expected payoff in the pricing stage, they would have the same (local) incentives to bid $b(v)$. To see that these incentives are indeed equal, consider a type $v$ partner who marginally increases her bid to $b(v)$. We just have to look at the change in expected payoff that results from trades with the marginal types $v$ and $s(v)$. She now becomes chooser with respect to these types (her marginal gain), whereas before she was proposing to those types (her marginal loss).

As chooser from a partner with valuation $v$ who proposes a price of $v$, she buys and hence gets $v-\frac{v}{2}=\frac{v}{2}$. As chooser from a partner with valuation $s(v)$, she sells and gets $\frac{s(v)}{2}$. Because both events happen with "probability" $f(v),{ }^{13}$ her marginal gain equals $\frac{v+s(v)}{2} f(v)$. As proposer, she would set a price of $v$. She would hence buy from another partner with valuation $v$ getting $\frac{v}{2}$ with probability $f(v)$. She would sell to $s(v)$, receiving $\frac{v}{2}$ with probability $f(v)$. Therefore, her marginal loss is $v f(v)$. Subtracting $\frac{v+s(v)}{2} f(v)$ from $v f(v)$ results in an overall marginal change in expected payoff equal to $\frac{s(v)-v}{2} f(v)$.

${ }^{13}$ Note that a decrease in $v$ increases $s(v)$, so that the probability of meeting a type $s(v)$ partner is given by $-\frac{d}{d v} F(s(v))=-\frac{d}{d v}(1-F(v))=f(v)$. 
Consider now a deviation by a type $s(v)$ who marginally increases her bid to $b(s(v-d v)){ }^{14}$ Her marginal gain from being chooser is $\left(\frac{3}{2} s(v)-\frac{v}{2}\right) f(v)$. Note that as chooser, she buys from $v$ and pays $\frac{v}{2}$ thus getting $s(v)-\frac{v}{2}$, and she sells to $s(v)$ receiving $\frac{s(v)}{2}$. Her marginal loss from deviating is $s(v) f(v)$. The difference in expected payoff from being chooser instead of proposer (with respect to the marginal types $v$ and $s(v)$ ) is $\frac{s(v)-v}{2} f(v)$. Thus, the marginal change in expected payoff from the pricing stage is the same for $v$ and $s(v)$.

In equilibrium, this change in expected payoff has to equal the change in transfers in the auction. The latter includes the direct effect of an increase in $b(v)$ on payments and on winning probabilities. By increasing the bid type $v$ is more likely to win, and she will hence have to pay the bid of the marginal type $b(v)$, whereas before she was receiving this amount as payment. This happens with probability $2 f(v)$, which gives a marginal loss of $-4 b(v) f(v)$. But with probability $2 F(v)$, she remains a loser but now gets a larger payment. Her marginal gain is then $2 F(v) \frac{d}{d v} b(v)$. The difference in expected payoff in the auction adds up to $-4 b(v) f(v)-2 F(v) \frac{d}{d v} b(v)$. In equilibrium, the marginal loss and the marginal gain from deviating must cancel out. Therefore the following differential equation has to be fulfilled:

$$
2 F(v) \frac{d}{d v} b(v)+4 b(v) f(v)=\frac{s(v)-v}{2} f(v) .
$$

The next Theorem provides an equilibrium bidding function $b_{N}(v)$ that solves this differential equation and is indeed U-shaped.

Theorem 1. The following strategies constitute an equilibrium of the dissolution game.

- In the first stage, both partners bid according to the following bidding function,

$$
b_{N}(v)=\left\{\begin{array}{cl}
\frac{\frac{1}{2} \int_{0}^{v}(s(t)-t) F(t) f(t) d t}{2 F^{2}(v)} & \text { if } v \leq v^{\text {med }} \\
\frac{\frac{1}{2} \int_{v}^{1}(t-s(t))(1-F(t)) f(t) d t}{2(1-F(v))^{2}} & \text { if } v>v^{\text {med }},
\end{array}\right.
$$

where

$$
s(v):=F^{-1}(1-F(v))
$$

- In the pricing stage, the proposer sets a price equal to her valuation.

The equilibrium bidding functions are strictly decreasing for valuations below the median $v^{\text {med }}$ and strictly increasing for $v>v^{\text {med }}$. In addition, we have that $b_{N}(v)=b_{N}(s(v))$, that is, for any $v$, we have that the mass of valuations that submit a higher bid is equally distributed on valuations smaller than $v$ and valuations that are larger than $v$. Note that the result does not require the cdf to be symmetric. The most important property of the equilibrium in Theorem 1 is that it renders an efficient dissolution of the partnership.

Corollary 1. The equilibrium is ex post efficient.

Waiting for the other to propose. If partners are ignorant about the possibility of negotiations (e.g., because they are not explicitly stated in the partnership agreement), either party may end up waiting for the other to name a price, as neither wants to propose. The time it takes to reach an agreement might impose costs on the parties as it may prevent them from either getting involved in other ventures or from running the business. This costly and time-consuming route can be modelled as a war of attrition.

${ }^{14}$ Deviations by decreasing the bid are computationally more involved and they require an Envelope-Theorem argument. See the proof of Theorem 1 (in the Appendix) for details. 
Let $b_{W}(v)$ denote the time at which a party with valuation $v$ quits this war of attrition (and makes a price offer), given that the other party has not yet quit. Note that $b_{W}(v)$ reflects the cost incurred by both parties when the first to quit has valuation $v$. As partners with extreme valuations are more reluctant to name a price, they will wait longer. Relying on arguments similar to the ones given in Section 3, we show that $b_{W}(v)$ being a symmetric U-shaped function is consistent with equilibrium behavior.

Theorem 2. The following strategies constitute an equilibrium of the war of attrition game.

- In the war of attrition both partners quit according to the following function,

$$
b_{W}(v)= \begin{cases}\int_{v}^{v^{\text {med }}} \frac{(s(t)-t) f(t)}{4 F(t)} d t & \text { if } v \leq v^{\text {med }} \\ \int_{v^{\text {med }}}^{v} \frac{(t-s(t)) f(t)}{4(1-F(t))} d t & \text { if } v>v^{\text {med }}\end{cases}
$$

where

$$
s(v):=F^{-1}(1-F(v)) .
$$

- In the pricing stage, the proposer sets a price equal to her valuation.

Note that in the war of attrition, both parties incur the cost of waiting, whereas in the negotiations, any payment is a transfer from one party to the other: the war of attrition achieves allocative efficiency but it generates inefficient costs of waiting. A consequence of these efficiency losses is that partners, independently of their valuation, prefer to negotiate immediately rather than play the war of attrition game described in this section.

Corollary 2. A partner's expected payoff in the dissolution game with immediate negotiations is always strictly higher than her payoff in the war of attrition.

A unified framework. As argued in the Introduction, both negotiations and waiting for the other to propose are consistent with the rules of the buy-sell clause. Corollary 2 suggests that it is preferable that partners negotiate (with negotiations starting immediately when the deadlock occurs) rather than enter into a war of attrition. But as the buy-sell clause does not dictate this, an important question is whether partners (who are aware of all possibilities) agree to negotiate immediately after the deadlock occurs (thus minimizing the cost of waiting). To analyze this question, we extend our model and allow for the possibility of a strategic delay of negotiations.

The unified dissolution game begins at $t=0$ when the deadlock occurs. We assume that it is costly for agents to stay in a deadlocked partnership and, as in Section 3, we normalize the marginal cost of staying in the partnership to one. At any point in time $t$, each partner can either propose a price, offer to negotiate, or stay in the deadlocked partnership and wait for the other partner to propose a price. Going to court is also a feasible action according to the rules of the buy-sell clause, but it is dominated by proposing a price. ${ }^{15}$ Whenever one partner makes a price offer, the other partner has to decide whether to buy or sell at that price and the game ends. If both offer a price at the same time, the proposer is determined randomly by the flip of a fair coin. All actions following the price offer take place instantaneously. Whenever a partner offers to negotiate (and the other does not make a price offer at the same time), the other partner can then decide to either accept or reject that offer. If it is accepted, or if both offer negotiations at the same time, these commence. It should be noted that negotiating is not considered to be a time-consuming (and thus costly) activity. Whereas in the war of attrition costly delay is used to screen types, in

${ }^{15}$ Note that here we model the court as a fair but uninformed body which will resolve the dispute by allocating the partnership to either partner with equal probability by setting a purchase price that depends only on common value components. 
negotiations payments to the other partner serve as the screening device. Therefore, as before, negotiations are modelled as an ascending auction with a fast clock on bids where the winner pays the loser. The loser proposes a price and the other partner decides on whether to buy or sell. If it is rejected, the game continues.

The following Theorem shows that the unified dissolution game is efficient, that is, it has an equilibrium where negotiations start without delay and the resulting allocation is ex post efficient.

Theorem 3. The unified dissolution game is efficient.

The proof of Theorem 3 constructs an equilibrium at which partners negotiate and dissolve the partnership efficiently at $t=0$. As at any time negotiations are better than the war of attrition (starting at that time; see Corollary 2), in the constructed equilibrium, either partner always offers to negotiate, always accepts negotiations, and never proposes a price. The latter is optimal, given that both partners believe that an offer to negotiate will come immediately afterward.

Note that other dissolution mechanisms, in particular auctions as defined in Cramton, Gibbons, and Klemperer (1987), can be embedded in this framework as well. If a partnership agreement specifies that partners must dissolve by using an auction, then auctions will not give rise to delay either. Both partners will optimally start the auction as soon as the deadlock occurs, as there is no benefit in delaying it because no new information can be gained from waiting. Consequently, by imposing a fast clock on bids, an auction would be efficient as well.

\section{Extensions}

- So far, we have examined the performance of buy-sell clauses in an independent private values model (IPV). We have shown that with IPV, buy-sell clauses cannot be dismissed for efficiency issues only. Our analysis can be extended to discuss the performance of buy-sell clauses when valuations are interdependent and only one party is informed. The purpose of this extension is threefold: (i) to relate our work to the recent contribution by Jehiel and Pauzner (2006) on partnership dissolution with interdependent values and one-sided incomplete information, (ii) to discuss the robustness of results with respect to the IPV assumption, and (iii) to provide an example for an environment where the buy-sell clause performs strictly better than a standard auction. ${ }^{16}$

Jehiel and Pauzner (2006) study an asymmetric setting where only one partner has private information which affects the valuations of both agents. They show that whenever first-best efficiency cannot be attained, the second-best outcome can be achieved if two different prices $p^{\text {sell }}$ and $p^{\text {buy }}$ are offered to the informed party so that she can decide to buy (at $p^{\text {buy }}$ ), sell (at $p^{\text {sell }}$ ), or dissolve at the flip of a coin. ${ }^{17}$ Note that the buy-sell clause is different from this decentralized second-best procedure not only because it requires two different prices $p^{\text {sell }}$ and $p^{\text {buy }}$ to be offered to the informed party but also because they have to be determined by either a third party or by the partners before any information is learned.

If a buy-sell clause is used and the uninformed party were to name the buy-sell price, he might end up being worse off than after a court settlement. As the proposer, he faces a two-sided winner's curse. If he ends up as the sole owner of the partnership, this is because his valuation is (likely to be) low (otherwise the informed partner would have bought). Similarly, if he is selling, this is because valuations are (likely to be) high. Due to these adverse selection problems, ${ }^{18}$ the uninformed party when proposing may get less than his individually rational payment, hence

\footnotetext{
${ }^{16}$ We summarize the main results here; a formal analysis can be found in de Frutos and Kittsteiner (2007).

${ }^{17}$ The first-best can always be attained if agents can observe their payoffs before monetary transfers are made (see Mezzetti, 2004). In Mezzetti's two-stage mechanism, the partnership is first allocated, then the owner experiences its value and reports it. Final transfers are contingent on the reports in the two stages.

${ }^{18}$ See Fieseler, Kittsteiner, and Moldovanu (2003) for a study on the negative effects of adverse selection for the efficiency of dissolution mechanisms.
} 
preferring to go for a court settlement. In contrast, if the informed were preselected as the proposer, her dilemma would be how to conceal information, as she wants to adhere to a strategy that does not fully reveal her valuation. Because of this, when the informed partner proposes, individual rationality holds for both parties but the partnership is dissolved efficiently only if types are extreme, that is, they are far enough away from the median. The extreme low types offer a price at which they always sell and the extreme high types offer a price at which they always buy; the other types fully reveal their type and propose a price which makes the uninformed indifferent to buying or selling. A comparison between the equilibrium allocation when the informed party proposes and Jehiel and Pauzner's second-best allocation shows that they coincide for uniformly distributed valuations because of the way the informed party proposes.

As in the IPV environment, there is a conflict as to who should propose. But now the uninformed partner may prefer to settle in court to ensure his status quo rather than to propose a price. For the informed party, this option is less attractive than proposing. Under the (credible) threat of ending up in court, the informed party will then name the price immediately. Thus, with endogenous proposer selection, the buy-sell clause may result in the second-best outcome, whereas an auction where the winner pays her bid cannot. This suggests that there could be an efficiency argument justifying the widespread use of buy-sell clauses.

\section{Conclusions}

- In this article, we have shown that widely used buy-sell clauses can dissolve partnerships efficiently. We have argued that the possibility of an efficient dissolution is related to how it is decided which partner proposes, a relationship that has not attracted sufficient attention in the economic or legal literature. Economic models so far have assumed the identity of the proposer as given, whereas the legal literature is ambiguous and imprecise with respect to this point. Our analysis suggests that lawyers who advise partners about the practical use of the clause should be aware of the broad road map that partners may follow when they must abide by the provisions laid down in the clause and their consequences. In particular, if partners' valuations are private, negotiations over the right to choose can render efficient dissolutions, whereas partners who simply wait for the other partner to name the price will incur costly delay.

Our main model considers two-parent partnerships with 50-50 ownership structure and independent private values. The first two restrictions do not greatly limit the applicability of our findings. ${ }^{19}$ On one hand, many partnerships do indeed have this 50-50 structure. On the other hand, buy-sell clauses can only be found in two-partner partnership agreements in which their underlying triggering event, a management deadlock, is most likely to occur if neither of the partners has exclusive control rights. Furthermore, lawyers recommend them for (roughly) equal shareholdings. The assumption of values being private may seem inappropriate for some partnerships, such as those between an inventor and a venture-capital fund. Because of this, we have studied the robustness of our main results to modelling values as interdependent. We again find that the buy-sell clause performs well and, in addition, show that it can strictly outperform an auction. Whereas our results show that the buy-sell clause cannot be ruled out on the grounds of efficiency, reasons outside our formal model may favor or discriminate against other contractual arrangements. ${ }^{20}$ For example, extensive case law might lead partners to prefer the buy-sell clause to an auction.

Partnership agreements usually contain several termination provisions, and each of them applies to a specific, predefined triggering event (e.g., deadlock, end of purpose, a partner wishes

\footnotetext{
${ }^{19}$ As our model is continuous in shares, we conjecture that our results will not change much if we slightly depart from the 50-50 assumption.

${ }^{20}$ If valuations are asymmetrically distributed, efficiency will not be guaranteed with a buy-sell clause or with an auction. It is not clear to us which mechanism will perform better in this environment. Any comparison must rely on particular distributional specifications (see de Frutos, 2000).
} 
to exit the venture, etc.). Put or call options, which allow one party to either sell or buy the other partner's shares at a prespecified price, are also frequently discussed as a way of dissolving partnerships, although they are rarely used in case of a deadlock. Options perform badly in allocating ownership rights efficiently, but are useful for mitigating the double-moral hazard problem in partners' investment decisions. For example, Noldeke and Schmidt (1998) show that an option contract might lead to efficient investment prior to the dissolution (see also Chemla, Habib, and Ljungqvist, 2007).

\section{Appendix}

Proof of Lemma 1. It is straightforward and it is hence omitted.

Proof of Lemma 2. If the bidding strategies in the negotiation stage are U-shaped, a proposer who bid $\widehat{b}$ has updated beliefs given by (2). It is then easy to verify that $F^{C}(x)$ satisfies the standard hazard rate conditions (1) for any $x \in[0$, $\left.v^{*}\right] \cup\left[v^{* *}, 1\right]$.

Because for any price $p$ the chooser optimally buys if and only if $v_{C}>p$, the proposer's utility when setting a price of $p$ is given by

$$
U^{P}\left(v_{P}, p\right)=\left(v_{P}-\frac{p}{2}\right) F^{C}(p)+\frac{p}{2}\left(1-F^{C}(p)\right)
$$

For any price $p \in\left[v^{*}, v^{* *}\right]$, the proposer is equally likely buyer and seller because

$$
F^{C}(p)=\frac{F\left(v^{*}\right)}{F\left(v^{*}\right)+1-F\left(v^{* *}\right)}=\left(\frac{1-F\left(v^{* *}\right)}{F\left(v^{*}\right)+1-F\left(v^{* *}\right)}\right)=\left(1-F^{C}(p)\right) .
$$

Consequently, setting $p=v_{P}$ in the pricing stage is optimal. Q.E.D.

Proof of Theorem 1. Consider a bidder with valuation $v$ smaller than $v^{\text {med }}$ who bids $b(\widehat{v})$ when the other bidder bids according to (3). Let $U(v, \widehat{v})$ denote the interim utility (in the dissolution game) of this bidder. By imitating a bidder of type $\widehat{v}$, she will be a chooser in the pricing stage if the other agent's valuation is within the interval $[\widehat{v}, s(\widehat{v})]$ and a proposer otherwise. $U(v, \widehat{v})$ can be decomposed in the expected payoff from being chooser (denoted by $\left.U^{C}(v, \widehat{v})\right)$ and proposer (denoted by $U^{P}(v, \widehat{v})$ ) in the pricing stage, and the payments she expects to receive/pay in the auction. Her expected utility is then

$$
U(v, \widehat{v})=U^{P}(v, \widehat{v})+U^{C}(v, \widehat{v})-\int_{\widehat{v}}^{s(\widehat{v})} b(x) f(x) d x+2 F(\widehat{v}) b(\widehat{v}) .
$$

Differentiating this overall expected utility with respect to its second argument, we have

$$
\begin{aligned}
U_{2}(v, \widehat{v})= & U_{2}^{P}(v, \widehat{v})+U_{2}^{C}(v, \widehat{v})-b(s(\widehat{v})) f(s(\widehat{v})) \frac{d s(\widehat{v})}{d \hat{v}} \\
& +3 b(\widehat{v}) f(\widehat{v})+2 F(\widehat{v}) \frac{d b(\widehat{v})}{d \hat{v}} \\
= & U_{2}^{P}(v, \widehat{v})+U_{2}^{C}(v, \widehat{v})+4 b(\widehat{v}) f(\widehat{v})+2 F(\widehat{v}) \frac{d b(\widehat{v})}{d \hat{v}},
\end{aligned}
$$

where the second equality follows from the symmetry of the bidding function with $b(\hat{v})=b(s(\hat{v}))$ and from the definition of $s(\cdot)$ that gives $f(s(\widehat{v})) \frac{d s(\widehat{v})}{d \widehat{v}}=-f(\widehat{v})$.

For $b(\cdot)$ to be an equilibrium strategy, it must be optimal for type $v$ to bid $b(v)$, which provides the following necessary condition,

$$
\left.U_{2}(v, \hat{v})\right|_{\hat{v}=v}=0 \quad \text { for all } v \in\left[0, v^{\text {med }}\right]
$$

We must show that $\max _{\widehat{v}} U(v, \widehat{v})=U(v, v)$. Note that we only need to show this for $\widehat{v} \leq v^{\text {med }}$ by the symmetry of $b(\cdot)$. Because the probability of winning, the payments, and the information revealed are exactly the same when bidding $b(\hat{v})$ and $b(s(\hat{v}))$, a deviation to a bid $b(\widehat{v})$ with $\widehat{v}>v^{\text {med }}$ is equivalent to deviating to a bid $b(s(\tilde{v}))$ for some $\tilde{v} \leq v^{\text {med }}$. In order to derive $U_{2}(v, \hat{v})$, we first compute $U_{2}^{P}(v, \hat{v})$. A losing bidder who bid $b(\widehat{v}) \in[b(0), b(1)]$ correctly infers that the other partner's valuation is either smaller than $\hat{v}$ or larger than $s(\hat{v})$. She uses this information to update her beliefs. Consequently, she proposes a price $p$ which maximizes

$$
U_{\widehat{v}}(v, p)=\left(v-\frac{p}{2}\right) F_{\widehat{v}}^{C}(p)+\frac{p}{2}\left(1-F_{\widehat{v}}^{C}(p)\right),
$$


where

$$
F_{\widehat{v}}^{C}(x)=\left\{\begin{array}{ccc}
\frac{F(x)}{2 F(\widehat{v})} & \text { if } & x \in[0, \widehat{v}] \\
\frac{F(\widehat{v})}{2 F(\widehat{v})} & \text { if } & x \in[\widehat{v}, s(\widehat{v})] \\
\frac{F(x)-F(s(\widehat{v}))+F(\widehat{v})}{2 F(\widehat{v})} & \text { if } & x \in s(\widehat{v}), 1] .
\end{array}\right.
$$

Differentiating the proposer's utility gives

$$
\frac{d}{d p} U_{\widehat{v}}(v, p)=\left\{\begin{array}{cccc}
(v-p) \frac{f(p)}{2 F(\widehat{v})}-\frac{F(p)}{2 F(\widehat{v})}+\frac{1}{2} & \text { if } & p \leq \widehat{v}, \\
0 & \text { if } & p \in(\widehat{v}, s(\widehat{v})) \\
(v-p) \frac{f(p)}{2 F(\widehat{v})}-\frac{F(p)-1+2 F(\widehat{v})}{2 F(\widehat{v})}+\frac{1}{2} & \text { if } & p \geq s(\widehat{v}) .
\end{array}\right.
$$

It is easy to see from this expression that the optimal price depends on $\hat{v}$. Two cases have to be distinguished. If $\widehat{v} \leq v$, then the following two inequalities hold:

$$
\begin{array}{cc}
(v-p) \frac{f(p)}{2 F(\widehat{v})}-\frac{F(p)}{2 F(\widehat{v})}+\frac{1}{2}>0 & \text { for } p \leq \widehat{v}, \text { and } \\
(v-p) \frac{f(p)}{2 F(\widehat{v})}-\frac{F(p)-1+2 F(\widehat{v})}{2 F(\widehat{v})}+\frac{1}{2}<0 & \text { for } p \geq s(\widehat{v}) .
\end{array}
$$

Hence, setting a price in the interval $[\widehat{v}, s(\widehat{v})]$ is optimal, resulting in a utility as proposer equal to

$$
U^{P}(v, \widehat{v})=\left(v-\frac{1}{2} p^{o p t}\right) F(\widehat{v})+\frac{1}{2} p^{o p t}(1-F(s(\widehat{v})))=v F(\widehat{v}) .
$$

Because $\widehat{v} \leq v$, we further obtain $\lim _{\widehat{v} / v} U_{2}^{P}(v, \widehat{v})=v f(v)$.

Consider now that $v^{\text {med }} \geq \widehat{v} \geq v$. In this case, we have

$$
\begin{gathered}
(v-\widehat{v}) \frac{f(\widehat{v})}{2 F(\widehat{v})}-\frac{F(\widehat{v})}{2 F(\widehat{v})}+\frac{1}{2} \leq 0 \quad \text { and } \\
(v-p) \frac{f(p)}{2 F(\widehat{v})}-\frac{F(p)-1+2 F(\widehat{v})}{2 F(\widehat{v})}+\frac{1}{2}<0 \quad \text { for all } \quad p \geq s(\widehat{v}) .
\end{gathered}
$$

The optimal price must hence satisfy $p^{\text {opt }} \leq \widehat{v}$. Consequently, the utility as proposer is now equal to

$$
\begin{aligned}
U^{P}(v, \widehat{v}) & =\left(v-\frac{1}{2} p^{o p t}\right) F\left(p^{o p t}\right)+\frac{1}{2} p^{o p t}\left[F(\widehat{v})-F\left(p^{o p t}\right)+1-F(s(\tilde{v}))\right] \\
& =p^{o p t}\left(F(\widehat{v})-F\left(p^{o p t}\right)\right)+v F\left(p^{o p t}\right),
\end{aligned}
$$

where $p^{o p t}$ satisfies the following first-order condition:

$$
\left(v-p^{o p t}\right) f\left(p^{o p t}\right)-F\left(p^{o p t}\right)+F(\widehat{v})=0 .
$$

Because $\lim _{\widehat{v} \backslash v} p^{o p t}=v$, we obtain ${ }^{21}$

$$
\begin{aligned}
\lim _{\widehat{v} \backslash v} U_{2}^{P}(v, \widehat{v}) & =\lim _{\widehat{v} \backslash v}\left[F(\widehat{v})-F\left(p^{o p t}\right)-\left(p^{o p t}-v\right) f\left(p^{o p t}\right)\right] \frac{d}{d \widehat{v}} p^{o p t}+p^{o p t} f(\widehat{v}) \\
& =\lim _{\widehat{v} \backslash v} p^{o p t} f(\widehat{v})=v f(v) .
\end{aligned}
$$

The analysis above ensures that $\left.U_{2}^{P}(v, \hat{v})\right|_{\hat{v}=v}=v f(v)$ for all $\hat{v} \leq v^{\text {med }}$.

We now compute $U_{2}^{C}(v, \hat{v})$. As the proposer always sets a price equal to her valuation, the expected utility as chooser will be

$$
U^{C}(v, \widehat{v})=\left\{\begin{array}{cc}
\int_{\widehat{v}}^{v}\left(v-\frac{x}{2}\right) f(x) d x+\int_{v}^{s(\widehat{v})} \frac{x}{2} f(x) d x & \text { if } \widehat{v} \leq v \\
\int_{\widehat{v}}^{s(\widehat{v})} \frac{x}{2} f(x) d x & \text { if } \widehat{v} \geq v .
\end{array}\right.
$$

Differentiating the chooser's utility with respect to $\hat{v}$ yields

$$
U_{2}^{C}(v, \widehat{v})= \begin{cases}\left(\frac{\widehat{v}-s(\widehat{v})-2 v}{2}\right) f(\widehat{v}) & \text { if } \widehat{v} \leq v \\ -\left(\frac{\widehat{v}+s(\widehat{v})}{2}\right) f(\widehat{v}) & \text { if } \widehat{v} \geq v\end{cases}
$$

${ }^{21}$ To make sure that $p^{\text {opt }}$ is uniquely defined (given $v$ and $\widehat{v}$ ), we need the hazard rate condition to hold. For the complete argument, see McAfee (1992). 
Evaluating $U_{2}^{C}(v, \widehat{v})$ at $v=\widehat{v}$ gives $U_{2}^{C}(v, v)=-\left(\frac{s(v)+v}{2}\right) f(v)$. Putting these results together, the first-order condition (A2) becomes

$$
-\left(\frac{s(v)-v}{2}\right) f(v)+2 F(v) \frac{d}{d v} b(v)+4 b(v) f(v)=0 .
$$

For (A2) to hold at $v=0$, we need that $b(0)=\frac{1}{8}$. Thus, a differentiable equilibrium has to be a solution of the boundary value problem determined by (A4) and the terminal condition $b(0)=\frac{1}{8}$. Note that the differential equation (A4) can be written as

$$
\frac{s(v)-v}{2} F(v) f(v)=\frac{d}{d v}\left(2 b(v) F^{2}(v)\right),
$$

and then integrated to obtain (3).

We next show that bidding $b(v)$ indeed does not result in a lower payoff (for a bidder with valuation $v$ ) than bidding $b(\widehat{v})$ with $\widehat{v} \leq v^{\text {med }}$. Observe first that for $\widehat{v} \leq v$, we have that

$$
U_{2}(v, \widehat{v})=-\frac{s(\widehat{v})-\widehat{v}}{2} f(\widehat{v})+2 F(\widehat{v}) \frac{d}{d v} b(\widehat{v})+4 f(\widehat{v}) b(\widehat{v}),
$$

with $U_{2,1}(v, \widehat{v})=0$, and therefore a bid of $b(\widehat{v})$ does not give larger payoffs than a bid of $b(v)$. Assume next that $\widehat{v} \geq v$. To show the optimality of $b(v)$ in this case, it is sufficient to show that $U_{2,1}(v, \widehat{v}) \geq 0$ for all $v \leq \widehat{v} \leq v^{\text {med }}$ (see McAfee, 1992). Using the abbreviation $p_{v}:=\frac{\partial}{\partial v} p^{o p t}$ we have that $U_{2,1}(v, \widehat{v})=U_{2,1}^{P}(v, \widehat{v})=p_{v} f(\widehat{v})$.

Using (A3), we obtain that

$$
p_{v}=-\frac{f\left(p^{o p t}\right)}{\left(v-p^{o p t}\right) f^{\prime}\left(p^{o p t}\right)-2 f\left(p^{o p t}\right)},
$$

which shows that

$$
\begin{aligned}
U_{2,1}(v, \widehat{v}) & =\frac{f\left(p^{o p t}\right) f(\widehat{v})}{2 f\left(p^{o p t}\right)-\left(v-p^{o p t}\right) f^{\prime}\left(p^{o p t}\right)}=\frac{f\left(p^{o p t}\right) f(\widehat{v})}{2 f\left(p^{o p t}\right)-\frac{F\left(p^{o p t}\right)-F(\widehat{v})}{f\left(p^{o p t}\right)} f^{\prime}\left(p^{o p t}\right)} \\
& =\frac{f(\widehat{v})}{\left.\frac{d}{d p}\right|_{p=p^{o p t}}\left(p+\frac{F(p)-F(\widehat{v})}{f(p)}\right)} \geq 0,
\end{aligned}
$$

where the second equality follows from the optimality of $p^{\text {opt }}$ (recall (A3)) and the last inequality from the hazard rate conditions (1).

We can hence conclude that the candidate equilibrium bid maximizes the expected utility in (A1). The case $v>$ $v^{\text {med }}$ can be shown similarly and it is hence omitted. Finally, partners' updated beliefs following a bid below $b_{N}(0)$ (above $\left.b_{N}(1)\right)$ coincide with those when the bid was $b_{N}(0)\left(b_{N}(1)\right)$. Bids outside the set of equilibrium bids are always dominated by either the lowest or highest bid in the range of equilibrium bids. QE.D.

Proof of Theorem 2. Arguments are similar to those in the proof of Theorem 1 and it is hence omitted.

Proof of Corollary 2. Because in both dissolution games the final allocation is the same, they differ only in the payments that partners make/receive, which in the war of attrition are given by the waiting costs. As partners' valuations are identical and independently distributed in any ex post efficient equilibrium, the difference in utilities between the two games is given by the difference in utilities for the "worst-off" types (e.g., $\left.v^{\text {med }}\right)$, as implied by the revenue equivalence theorem. The statement then follows from the fact that the utility of a partner with valuation $v^{\text {med }}$ is higher in the dissolution game with negotiations than in the war of attrition as

$$
U_{N}\left(v^{\text {med }}\right)=\frac{v^{\text {med }}}{2}+\int_{0}^{v^{\text {med }}}(s(z)-z) F(z) f(z) d z>\frac{v^{\text {med }}}{2}=U_{W}\left(v^{\text {med }}\right) .
$$

Q.E.D.

Proof of Theorem 3. Consider the following strategy: any type of any partner will always offer negotiations, always accept negotiations, and never name a price directly. After negotiations have been accepted, partners play according to the strategies described in Theorem 1.

Regarding players' beliefs about moves off the equilibrium path, if a partner names a price, beliefs are innocuous as the other has as a dominant strategy to buy if and only if her valuation is above this price. If negotiations are rejected, beliefs are not updated. Furthermore, the set of types for which the observed off-equilibrium move could have been worthwhile is empty. Clearly, it is neither profitable to reject negotiations nor to just wait, as this only increases the time costs. Furthermore, naming a price is always worse for any type of partner than offering negotiations. This immediately follows from Corollary 2. Naming a price straight away is (weakly) worse than the war of attrition, as otherwise any partner would name a price immediately in the war of attrition, and this is (strictly) worse than to offer negotiations. Q.E.D. 


\section{References}

Brooks, R. AND SPIER, K.E. “Trigger Happy or Gun Shy? Dissolving Common-Value Partnerships with Texas Shootouts.” Mimeo, Kellogg School of Management, 2004.

CADMAn, J. Shareholders' Agreements. London: Thomson, 2004.

Chemla, G., Habib, M., And LuUngqvist, A. "An Analysis of Shareholder Agreements.” Journal of the European Economic Association, Vol. 5 (2007), pp. 93-121.

Cramton, P., Gibbons, R., And Klemperer, P. “Dissolving a Partnership Efficiently.” Econometrica, Vol. 55 (1987), pp. 615-632.

De Frutos, M.A. “Asymmetric Price-Benefits Auctions.” Games and Economic Behavior, Vol. 33 (2000), pp. 48-71. AND KitTsteIner, T. Efficient Partnership Dissolution under Buy-Sell Clauses. Mimeo, Universidad Carlos III de Madrid, 2007.

Fieseler, K., Kittsteiner, T., And Moldovanu, B. "Partnerships, Lemons and Efficient Trade.” Journal of Economic Theory, Vol. 113 (2003), pp. 223-234.

Hauswald, R. And Hege, U. Ownership and Control in Joint Ventures: Theory and Evidence. CEPR Discussion Paper no. $4056,2003$.

HewitT, I. Joint Ventures. London: Sweet \& Maxwell, 2005.

Hoberman, J.M. "Practical Considerations for Drafting and Utilizing Deadlock Solutions for Non-Corporate Business Entities." Columbia Business Law Review, Vol. 2001 (2001), pp. 231-255.

Jehiel, P. AND PAUZNer, A. "Partnership Dissolution with Interdependent Valuations." RAND Journal of Economics, Vol. 37 (2006), pp. 1-22.

McAfEe, R.P. “Amicable Divorce: Dissolving a Partnership with Simple Mechanisms.” Journal of Economic Theory, Vol. 56 (1992), pp. 266-293.

Mezzetti, C. “Mechanism Design with Interdependent Valuations: Efficiency.” Econometrica, Vol. 72 (2004), pp. 16171626.

Morgan, J. “Dissolving a Partnership (Un)Fairly.” Economic Theory, Vol. 23 (2004), pp. 909-923.

NöLDEKE, G. AND SCHMIDT, K.M. "Sequential Investments and Options to Own.” RAND Journal of Economics, Vol. 29 (1998), pp. 633-653.

Stedman, G. And Jones, J. Shareholders’ Agreements. London: Longman, 1990.

Veugelers, R. And Kesteloot, K. "Bargained Shares in Joint Ventures among Asymmetric Partners: Is the Matthew Effect Catalyzing?” Journal of Economics, Vol. 64 (1996), pp. 23-51. 